\title{
The Effect of Different Concentration of Poloxamer 188 on Nanocrystalline Characteristics of Celery Herb Extract (Apium graveolens L.)

\author{
Henni Rosaini ${ }^{1}$, Harrizul Rivai ${ }^{2 *}$, Maria Dona Octavia ${ }^{1}$, Elva Yulia Rosanti ${ }^{1}$ and Indra Makmur ${ }^{1}$
}

${ }^{1}$ College of Pharmacy (STIFARM), Jl. Raya Siteba Kurao Pagang, Padang 25147, Indonesia

${ }^{2}$ Faculty of Pharmacy, Andalas University, Limau Manih Campus, Padang 25163, Indonesia

DOI: $\underline{10.36347 / \text { sajp.2021.v10i01.001 }}$

| Received: 22.12.2020 | Accepted: 04.01.2021 | Published: 11.01.2021

*Corresponding author: Harrizul Rivai

Abstract

Celery (Apium graveolens L.) is a plant from the Apiaceae family which contains apigenin compounds that can be used as an antihypertensive drug. Apigenin contained in celery has low solubility in water. One method to increase solubility is to create a nanocrystalline system. This study aimed to see the effect of differences in the concentration of Poloxamer 188 on the characterization of nanocrystalline formation of celery herb extracts. The results of the Particle Size Analyzer (PSA) show that the particle size distribution of formula 1 the concentration of Poloxamer $18840 \%$ with a grinding time of 6 hours is 1648.5 while for formula 2 the concentration of poloxamer $18850 \%$ with a grinding time of 5 hours is 1049.6 and formula 3 the concentration of poloxamer $18860 \%$ with a grinding time of 5 hours was 1483.2. The zeta potential value of each formula is $-11.2,-12.5$, and -8.9 . The X-ray diffractogram analysis shows the formula still maintains its crystallinity, which is indicated by the formation of sharp peaks in each formula. The surface morphology analysis shows formulas 1, 2, and 3 with a magnification of 500 times look irregular and no longer visible differences between extract powders herbs celery and poloxamer 188.

Keywords: Nanocrystal, celery, poloxamer 188, solubility, wet milling.

Copyright $($ C 2021 The Author(s): This is an open-access article distributed under the terms of the Creative Commons Attribution 4.0 International License (CC BY-NC 4.0) which permits unrestricted use, distribution, and reproduction in any medium for non-commercial use provided the original author and source are credited.

\section{INTRODUCTION}

Celery (Apium graveolens $\mathrm{L}$ ) is a type of herb used to treat hypertension. Celery is a plant from the Apiaceae family that grows spread throughout Europe, Asia, tropical and subtropical Africa. Celery contains flavonoids, saponins, $1 \%$ tannins, $0.033 \%$ essential oils, flavonoid-glucosides (apiin), apigenin, choline, asparagine, vitamins A, B, and C [1].

Based on research conducted by Saputra \& Fitria [2], apigenin contained in celery is a vasorelaxant or vasodilator (dilates blood vessels) with a contraction inhibiting mechanism caused by the release of calcium (a mechanism of action such as calcium antagonists). Gusniwati's [3] study revealed that apigenin levels in the thick ethanolic extract of celery stalks and leaves were $16.4 \%$ and $8.74 \%$, respectively. Apigenin is included in the class II biopharmaceutics classification system (BCS), which has low solubility and high permeability [4]. One of the newly developed methods to increase the solubility of substances in the nanocrystalline formulation.

Nanocrystals are defined as crystals having particle sizes in nanometers between $10-1000 \mathrm{~nm}$ [5].
Reducing the particle size in the nanometer range can increase the particles' surface area, saturation solubility, and dissolution rate so that the bioavailability of the drug can increase. The nanocrystalline system consists of water, a medicinally active substance, and a stabilizer [6].

Based on research conducted by Zhang et al. [7] that at the time of the dissolution test, the dissolved apigenin powder was $40 \%$ in 120 minutes. Meanwhile, the dissolved apigenin nanocrystals in the dissolution medium were $90 \%$ in 20 minutes.

This study is using Poloxamer 188 as a stabilizer to prevent aggregation. Poloxamer 188 is nontoxic and non-irritating. Poloxamer 188 consists of a hydrophilic polyoxyethylene chain and a hydrophobic polyoxypropylene chain. Hydrophobic chains can be adsorbed and produce interactions on the surface of drug crystals. Hydrophilic chains can cover drug particles, thus providing steric barriers and preventing aggregation. $[8,5]$.

Based on the above background, in this study, nanocrystals will be made between celery herb extracts 
with different concentrations of Poloxamer 188 as stabilizers using the wet-milling method. It is hoped that the preparation of nanocrystals of celery herb extract with poloxamer 188 is expected to form stable nanocrystals still.

\section{EXPERIMENTAL SECTION/MATERIAL AND METHODS Equipment}

Analytical digital scale (PrecisaXB 220A), Planetary Ball Mill (Retsch, Type PM 100). Rotary Evaporator (IKA Hb 10). Particle Size Analyzer, X-ray diffractometer (Philips X'Pert Proanalytical), Freeze dryer (Christ, alpha 1-2 LDplus), Scanning Electron Microscope (Hitachi S-3400N), Spray dryer (Bu-chi B2901), and other tools that support research.

\section{Materials}

Materials used in this study are celery herbs (Apium graveolens L), Poloxamer 188 (Merck), 96\% ethanol (Bratachem), Chloroform (Bratachem), methanol Pro analysis (Merck), distilled water (Ikaphermindo), and other ingredients.

\section{Sampling}

The sample used was celery herb (Apium graveolens L.) taken directly at Koto Laweh, Padang Panjang, West Sumatra, Indonesia.

\section{Plant identification}

Plant identification was carried out at Herbarium Andalas, Department of Biology, Faculty of Mathematics and Natural Sciences, Andalas University, Padang, Indonesia.

\section{Poloxamer 188 raw material inspection}

Poloxamer 188 examination was carried out according to the methods listed in the Handbook of Pharmaceutical Excipients $\left(6^{\text {th }}\right.$ ed. $)$ including description and solubility [8].

\section{Simplicia preparation}

In general, the manufacturing process of simplicia goes through several stages, namely, collecting raw materials, wet sorting, washing, chopping, drying, dry sorting, storage, and quality inspection [9].

\section{Characterization of celery herb simplicia}

Specific parameters include determination of water-soluble extract, determination of extracts that are soluble in ethanol. In contrast, non-specific parameters include determining drying losses, determining ash content, and determining acid insoluble ash content, Ethanol [10].

\section{Extract preparation}

The extract preparation in this research uses the maceration method. Dry simplicia is weighed as much as $400 \mathrm{~g}$, put in a tightly closed container, and immersed in $12 \mathrm{~L}$ of $50 \%$ ethanol until the simplicia is completely submerged. In the first 6 hours, the mixture was stirred occasionally and then left for 18 hours. After 24 hours, the mixture was filtered with a flannel cloth to separate the macerate and maceration residue. This process is carried out three times. All maserate was collected, followed by a solvent separation process with a rotary evaporator to obtain a thick extract. Calculate the yield got, weighed, and recorded [11].

\section{Extract characterization}

The specific characterization that was carried out included identity, organoleptic examination. The non-specific description that was carried out had the determination of water content, total ash content, and acid-insoluble ash content [10].

\section{Preparation of celery herb extracts powder}

The celery herb extract was weighed as much as $20 \mathrm{~g}$, then put into a $1 \mathrm{~L}$ glass beaker, then added with distilled water little by little until the extract was homogeneous. After that, add $1 \mathrm{~L}$ of distilled water and dry it using spray drying.

\section{Preparation of nanocrystals from herbal extracts of celery and Poloxamer 188}

Nanocrystals from celery herb extract and Poloxamer 188 were made with a design, as shown in Table 1 below.

Table-1: Design of nanocrystalline formulations from herbal extracts of celery and Poloxamer 188

\begin{tabular}{|l|l|l|l|}
\hline Formula & $\begin{array}{l}\text { Celery herb extract } \\
\text { powder }(\mathbf{g})\end{array}$ & $\begin{array}{l}\text { Poloxamer }(\boldsymbol{\%} \\
\text { w/w) }\end{array}$ & $\begin{array}{l}\text { Vol } \\
(\mathbf{m L})\end{array}$ \\
\hline F1 & 0.5 & 40 & \multirow{2}{*}{20} \\
\hline F2 & 0.5 & 50 & \\
\hline F3 & 0.5 & 60 & \multicolumn{2}{|c|}{} \\
\hline
\end{tabular}

Celery herb extract nanocrystals were prepared using the Top-down method by wet grinding. Poloxamer 188 was weighed according to the planned formula, dissolved in $20 \mathrm{~mL}$ distilled water. Then it was inserted into the chamber, which contains 34 units of zirconium ball mill with a diameter of $0.2 \mathrm{~cm}$ and a diameter of $0.5 \mathrm{~cm}$, as many as 34 pieces. The celery herb extract as much as $0.5 \mathrm{~g}$ is dispersed into the chamber. The grinding process is carried out using a planetary ball mill to form nanosuspension at $400 \mathrm{rpm}$, in formula 1 for 6 hours and formula 2 and 3 for 5 hours. The nanosuspension created was dried using a freeze dryer. Then, the physicochemical 
characterization of the nanocrystalline extract of celery was carried out.

\section{Physicochemical characterization of celery herb extracts nanocrystals}

\section{Particle Size Analyzer (PSA)}

Analysis of particle grains distribution uses the Particle Size Analyzer (PSA), which works on the principle of Diynamic Light Scattering. This method uses a dispersing medium to disperse the sample. The dispersing medium is distilled water. Measurement of the sample was carried out three times until two data were obtained with a difference of less than $20 \mathrm{~nm}$ [12].

\section{Zeta potential}

Zeta potential is a measure of the surface charge of the particles that are scattered in the dispersing medium. Nanoparticles with a zeta potential value smaller than $-30 \mathrm{mV}$ and more excellent than +30 $\mathrm{mV}$ because the higher the zeta potential value, the more it prevents flocculation, which is the colloid fusion event from small to large which has higher stability[13].

\section{X-Ray Diffraction (XRD)}

X-ray diffraction tests were performed on celery herb extract powder, Poloxamer 188, formula 1 , formula 2, and formula 3 . The powder XRD patterns were traced using $\mathrm{x}$-ray diffraction for samples under $\mathrm{Cu}-\mathrm{K}$ conditions, $40 \mathrm{kV}$ voltage, current $30 \mathrm{~mA}$ of radiation is scattered within the sample's crystal region, as measured by a vertical goniometer. The patterns were obtained using a $0.04^{\circ}$ step width with a detector resolution of $2 \theta$ (diffraction angle) between $10^{\circ}$ to $50^{\circ}$ at room temperature [7].

\section{Scanning Electron Microscope (SEM) Test}

The celery herb powder sample was placed in an aluminum sample holder and coated with palladium with a thickness of 15-20 mm. The sample was then observed for various magnifications. The voltage was adjusted at $20 \mathrm{kV}$, current of $25 \mathrm{~mA}$ for 10 minutes. This analysis will show the morphology of the celery herb extract powder's particle form, Poloxamer 188, formula 1 , formula 2 , and formula 3 [7].

\section{RESULTS AND DISCUSSION}

The results of the examination of the raw material for celery herb extract and poloxamer 188

The celery herb that was taken as much as $5 \mathrm{~kg}$ obtained 700 grams of dry simplicia. The results of specific and non-specific simplicia characteristics have met the Ministry of Health's requirements of the Republic of Indonesia [14]. The celery herb was extracted using the maceration method with $400 \mathrm{~g}$ of simplicia using $50 \%$ ethanol as a solvent. The extract was $76.3719 \mathrm{~g}$ with a yield of $19.09297 \%$. After that, the characterization of the celery herb extract was carried out. The results of specific and non-specific descriptions have met the Ministry of Health's requirements of the Republic of Indonesia [14].

The thin layer chromatography test revealed that the Rf value of apigenin was 0.35 using methanol: chloroform eluent, namely (0.5: 9.5) with silica gel GF254 as the stationary phase [15]. In this study, the Rf value was 0.357 for the comparison and sample, while for the mixture, it was 0.37. Poloxamer 188 examination includes the description: white granule shape, odorless, and tasteless. The solubility test for Poloxamer 188 is that $1 \mathrm{~g}$ of poloxamer 188 dissolves in $9 \mathrm{~mL}$ of water, $1 \mathrm{~g}$ of Poloxamer 188 is dissolved in 4 $\mathrm{mL}$ of ethanol.

\section{The physicochemical characteristics of celery herb extract nanocrystals}

\section{Particle Size Analyzer (PSA)}

The result of particle measurement in formula 1 is $1648.5 \mathrm{~nm}$, and the potential zeta value is -11.2 . In formula 2 , the particle size is 1049 , and the zeta potential value is -12.5 . In formula 3 , the particle size is 1483.2, and the zeta potential value is - 8.9. Based on these results, none of them meet the requirements. Only formula 2 is close to the conditions because the particle size requirements are $10-1000 \mathrm{~nm}$. It happens because, in formula 1 , more energy is expended with a grinding time of 6 hours. The greater the surface area and the concentration of Poloxamer 188, 40\% are not sufficient to cover the particles. Whereas in formulas 2 and 3, the particles' size may be due to the long storage time so that it is unstable and there is an overlap between particles.

\section{Potential zeta}

None of the potential zeta values meet the requirements because they are smaller than $-30 \mathrm{mV}$ and larger than $+30 \mathrm{mV}$ - the more extensive and farther the particle size, the greater the energy of repulsion. The polydispersity index value of the three formulas meets the requirements, which is smaller than 0.6. The polydispersity index value is more significant in formula 1 , namely 0.592 , formula 2 is 0.502 , and formula 3 is 0.456 .

\section{X-Ray Diffraction (XRD)}

To observe the diffraction pattern emanating from a particular crystal, and determine the crystal structure, follow the following factors:

1. The distance between similar atoms in the crystal structure is called d-spacing.

2. The angle of diffraction is also called the theta angle. A diffractometer measures an angle that multiplies the theta angle, which can be seen as 2 thetas.

3. The wavelength of light.

This combination of factors is known as the Braggs equation: $n \lambda=2 d \sin \theta$ 
Henni Rosaini et al., Sch Acad J Pharm, Jan, 2021; 10(1): 1-5

Where $\mathrm{n}$ is the diffraction amount, $\lambda$ is the wavelength $(\AA), d$ is the distance between similar atoms $(\AA), \theta$ is the theta angle. The data obtained are displayed in a signal intensity plot with 2 thetas. Peak intensity appears at specific values to identify constructive disturbances at absolute values, particular patterns for certain interplanetary distances. The crystal structure and the film thickness can be determined from the diffraction pattern [16].
The X-ray diffractogram analysis results using an X-ray diffractometer showed that the extract of celery was in the form of crystals characterized by sharp interference peaks. The difference in the concentration of Poloxamer 188 in the nanocrystalline formula did not affect the nanocrystalline interference height. The interference peaks of celery extract nanocrystals still retained their sharp peak shape. The sharp peaks indicate that the celery herb extract in the formulation is still crystalline (Figure 1).

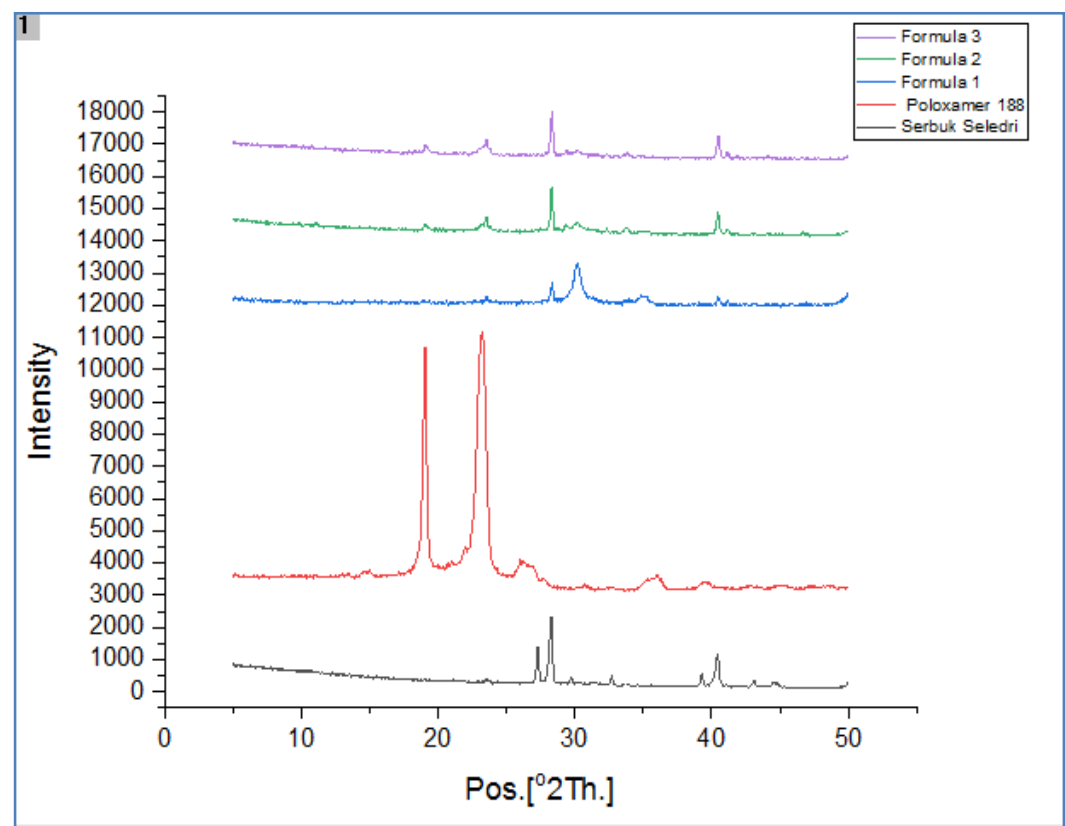

Fig-1: The X-ray diffractogram. (a) Celery herb extract, (b) Poloxamer 188, (c) Formula 1, (d) Formula 2, (e) Formula 3

\section{Scanning Electron Microscope}

Measurement of surface morphology using an SEM tool uses a 500x magnification to see the surface morphology. The celery herb extract's morphology looks like a chunk (Figure 2), and Poloxamer 188 looks like a sphere (Figure 3). Formula 1, formula 2, formula 3 with 500x magnification look irregular, and there is no longer any difference between celery herb extract and Poloxamer 188. The mixture of the two components can no longer be separated physically and morphologically from the powder of celery herb extract with Poloxamer 188 in formula 1, formula 2, and formula 3, as shown in Figures 4, 5, and 6.

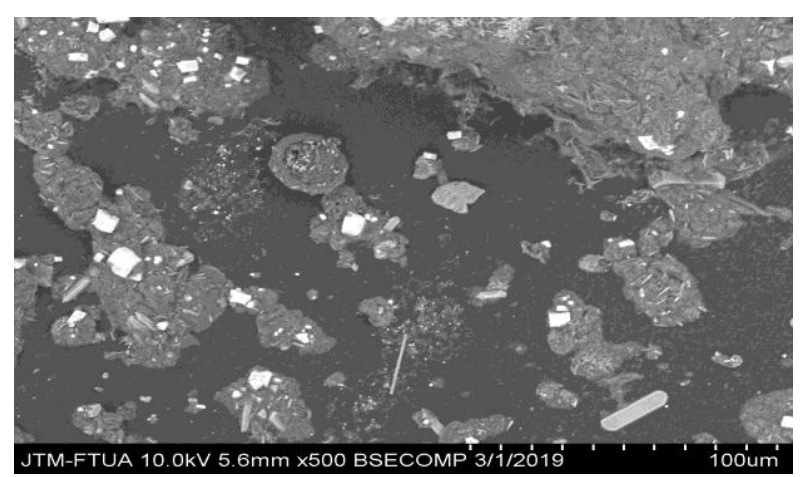

Fig-2: Morphology of scanning electron microscope extract of celery herb with 500x magnification

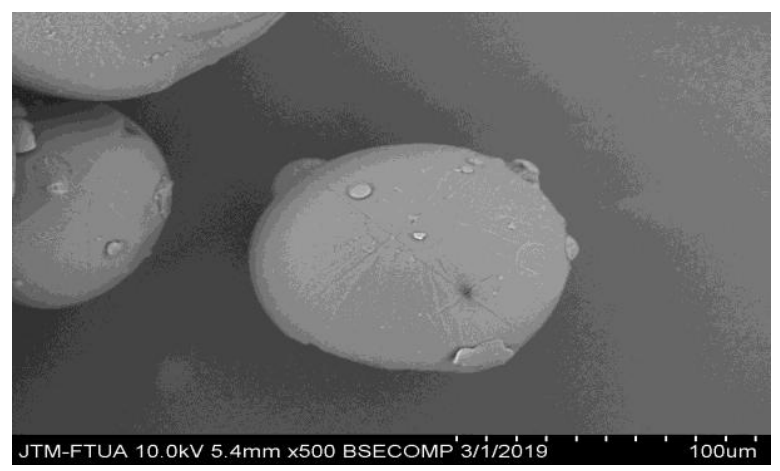

Fig-3: Morphology of scanning electron microscope Poloxamer 188 with 500x magnification

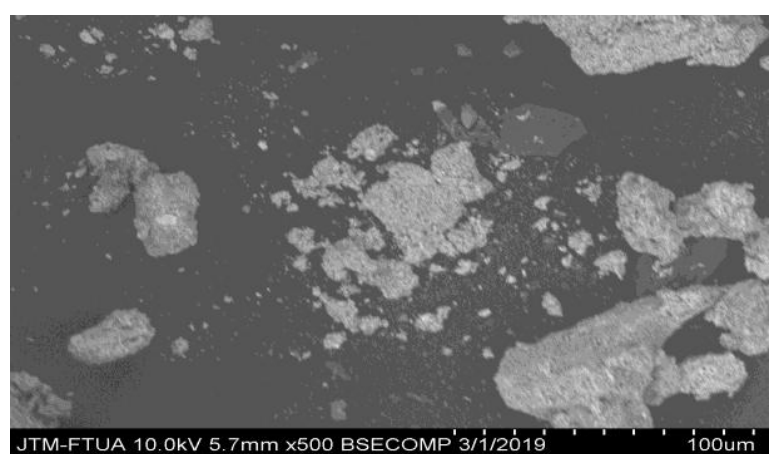

Fig-4: Morphology of scanning electron microscope formula 1 with 500x magnification 
Henni Rosaini et al., Sch Acad J Pharm, Jan, 2021; 10(1): 1-5

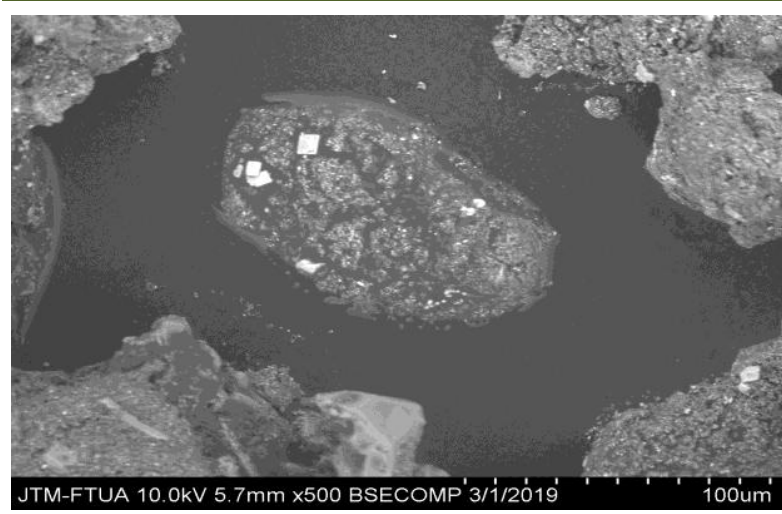

Fig-5: Morphology of scanning electron microscope formula 2 with 500x magnification

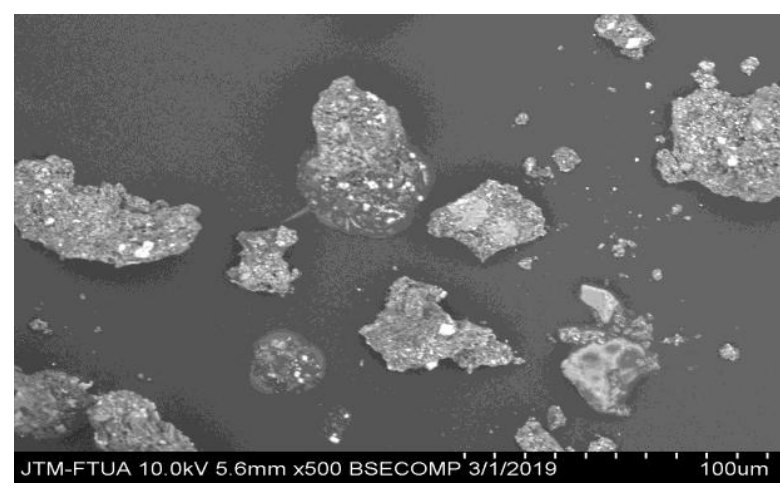

Fig-6: Morphology of scanning electron microscope formula 3 with 500x magnification

The results of measuring the particle size distribution of formula 1 with a grinding time of 6 hours at a concentration of poloxamer $18840 \%$ are still large, namely $1648.5 \mathrm{~nm}$, formula 2 with a grinding time of 5 hours at a concentration of $18850 \%$ poloxamer which is $1049.6 \mathrm{~nm}$ and formula 3 with a grinding time 5 hours at a $60 \%$ poloxamer concentration of $1483.2 \mathrm{~nm}$. It is also due to the long storage time after the freezedrying process so that the particles are unstable and form re-aggregation.

The surface morphology analysis results showed that formulas 1,2 , and 3 at a magnification of 500 times looked irregular, and there was no longer any difference between celery extract and Poloxamer 188. It indicates an interaction between the active substance of celery herb extract and the poloxamer 188 stabilizer molecules.

\section{CONCLUSION}

Based on research conducted on the manufacture of celery herb extract nanocrystals with different concentrations of Poloxamer 188 on the nanocrystalline characteristics of celery herb extract (Apium graveolens L.), it can be concluded that the optimal concentration of Poloxamer 188 has not been obtained. X-ray diffraction characterization showed a decrease in celery herb extracts' crystal intensity in all formulas compared to celery herb extracts but still showed sharp peaks.

\section{REFERENCES}

1. Menkes RI. Peraturan Menteri Kesehatan Republik Indonesia Nomor 6 Tahun 2016 Tentang Formularium Obat Herbal Asli Indonesia. Kementerian Kesehatan Republik Indonesia. Jakarta. 2016.

2. Saputra O, Fitria T. Khasiat Daun Seledri (Apium graveolens) Terhadap Tekanan Darah Tinggi Pada Pasien Hiperkolestrolemia. Jurnal Majority. 2016 Apr $1 ; 5(2): 120-5$

3. Gusniwati R. Isolasi dan Penetapan Kadar Apigenin pada Ekstrak Seledri (Apium graveolens. L) Secara KCKT. (Skripsi). Universitas Andalas. 2009.

4. Zhang J, Liu D, Huang Y, Gao Y, Qian S. Biopharmaceutics classification and intestinal absorption study of apigenin. International Journal of Pharmaceutics. 2012 Oct 15;436(1-2):311-7.

5. Liu P. Nanocrystal formulation for poorly soluble drugs. Dissertation. Finland: University of Helsinki. 2013.

6. Junyaprasert VB, Morakul B. Nanocrystals for enhancement of oral bioavailability of poorly watersoluble drugs. Asian journal of pharmaceutical sciences. 2015 Feb 1;10(1):13-23.

7. Zhang J, Huang Y, Liu D, Gao Y, Qian S. Preparation of apigenin nanocrystals using supercritical antisolvent process for dissolution and bioavailability enhancement. European Journal of Pharmaceutical Sciences. 2013 Mar 12;48(4-5):740-7.

8. Rowe RC, Sheskey P, Quinn M. Handbook of pharmaceutical excipients. Libros DigitalesPharmaceutical Press; 2009.

9. Sirait M. Cara Pembuatan Simplisia. Jakarta: Departemen Kesehatan Republik Indonesia. 1985.

10. Indonesia DK. Parameter standar umum ekstrak tumbuhan obat. Jakarta: Departemen Kesehatan Republik Indonesia. 2000.

11. Badan POM. Monografi Ekstrak Tumbuhan Obat Indonesia (Volume 1) Jakarta. Badan POM RI. 2004.

12. Rawle A. Basic Principles of Particle Size AnalysisTechnical Paper of Malvern Instruments. Worcestershire. The United Kingdom. 2010:1012-7.

13. Murdock RC, Braydich-Stolle L, Schrand AM, Schlager JJ, Hussain SM. Characterization of nanomaterial dispersion in solution prior to in vitro exposure using dynamic light scattering technique. Toxicological sciences. 2008 Feb 1;101(2):239-53.

14. Kemenkes RI. Suplemen I Farmakope Herbal Indonesia. Jakarta: Kementerian Kesehatan Republik Indonesia. 2010.

15. Juwita RZ. Validasi metode penentuan kadar apigenin dalam ekstrak seledri dengan kromatografi cair kinerja tinggi. Undergraduate Thesis. Bogor: Institut Pertanian Bogor. 2008.

16. Kenkel J. Analytical chemistry for technicians. Boca Raton: CRC Press; 2002 Oct 29. 275-9. 